\title{
Morbilidad en un centro penitenciario de Colombia
}

\section{Morbidity in a penitentiary center of Colombia}

\author{
Amanda Constanza Riańo ${ }^{1}$, Sandra Lucía Chamorro Mora ${ }^{1}$
}

\section{RESUMEN}

El presente estudio analizó la situación de salud de los internos del Centro Penitenciario y Carcelario del Municipio de Mocoa, Putumayo, Colombia donde se presentan condiciones de hacinamiento y precariedad en la salud. objetivo: Describir la situación de salud de los reclusos en el Centro Penitenciario y Carcelario del Municipio de Mocoa, Putumayo, durante el ańo 2013. Método: Estudio observacional, tipo descriptivo de corte transversal. Mediante la aplicación de encuestas estructuradas a una muestra de 103 internos, una guía observacionaly la revisión documental de los registros individuales de

\begin{abstract}
The present study analyzed the health situation of the inmates of the Penitentiary and Prison Center of the Municipality of Mocoa where conditions of overcrowding, precariousness in health and death. Objective: To describe the health situation of inmates in the Penitentiary and Jail Center of the Municipality of Mocoa during the period January to December 2013. Method: Observational study, descriptive type of cross section. Through the application of structured surveys to a sample of 103 inmates, an observational guide and the documentary review of the individual records of service provision, the
\end{abstract}

\section{Historial del artículo:}

Fecha de recepción: 15/06/2016

Fecha de aceptación: 16/01/2017

1 Universidad Surcolombiana. Programa de Especialización en Epidemiologia, Facultad de Salud, Neiva, Colombia.

Correspondencia: Sandra Lucia Chamorro Mora. Dirección: Calle 9 No. 15-25, Neiva, Huila. Teléfono: (8) 8754753. Correo electrónico: sandrach95@gmail.com

Como citar este artículo: Riańo AC, Chamorro-Mora S. Morbilidad en un centro penitenciario de Colombia. Revista de la Facultad de Ciencias de la Salud de la Universidad del Cauca. 2019; 21 (1):16-22 
prestación de servicio, se analizó la situación de salud de los internos del centro penitenciario. Resultados: Se identificó una población depredominio masculino entre los 20 y 49 años, donde 30.3\% corresponde a grupos indígenas con una baja escolaridad. Se encontraron condiciones de hacinamiento e insalubridad. Adicionalmente los internos cuentan con un limitado e inoportuno acceso a los servicios de salud. Un $77.9 \%$ de los internos estudiados manifestó enfermar luego de ingresar al penal. Conclusiones: Se concluye que estepenal refleja de cierta forma las condiciones del Departamento del Putumayo, teniendo en cuenta las similitudes de las características sociodemognáficas de los internos encuestados. El análisis de morbilidad permitió encontrar diferencias en cuanto al comportamiento comparado con otrospenales del país, dados los escasos reportes de infecciones de transmisión sexualy enfermedades crónicas.

Palabras claves: Prisiones, morbilidad, estado de salud, Colombia. (DeCS)

\section{INTRODUCCIÓN}

Múltiples investigaciones se han realizado al respecto en los centros penitenciarios a nivel nacional e internacional. Miles de hombres y mujeres alrededor del mundo se encuentran cautivos en estos centros y viven su día a día en condiciones de insalubridad, hacinamiento, enfermedad y muerte. La diversidad de las problemáticas abordadas en estas investigaciones, va desde análisis de morbilidad con énfasis en enfermedades de transmisión sexual, enfermedades mentales, consumo de sustancias psicoactivas, hasta calidad de los servicios de salud, entre otros $(1,2)$.

Sin duda las condiciones de salubridad y hacinamiento, junto con la alta incidencia de enfermedades secundarias a estas, la vulneración de derechos de los internos y en especial el derecho a la salud, son una constante en los análisis de salud (2). Sumado a esto, la calidad de prestación de servicios de salud que se traduce en servicios médicos de baja calidad, inoportunidad en atención de media y alta complejidad, contribuyen al deterioro de salud de los presos, reflejando un sistema de salud inexistente donde los presos escasamente sobreviven.

En Colombia, el panorama no es diferente. Informes de organizaciones humanitarias internacionales y del Ministerio Público, junto a estudios de tipo epidemiológico, health situation of inmates of the penitentiary center was analyzed. Results: A predominantly male population was identified between 20 and 49 years old, where 30.37\% correspond to indigenous groups with a low level of schooling, internal, who, as in the rest of the country, survive in overcrowded and unhealthy conditions. There is a limited and inopportune access to health services, where $77.94 \%$ of inmates said they became ill after entering the prison. Conclusions: It is concluded that this prison reflects in some way the conditions of Putumayo, taking into account the similarities of the sociodemographiccharacteristicsof theinmatessurveyed. The analysis of morbidity allowed to find differences in the behavior compared to other prisons in the country, given the few reports of sexually transmitted infections and chronic diseases.

Key words: Prisons, morbidity, health status, Colombia. (MeSH)

muestran que nuestras cárceles presentan altos índices de hacinamiento y condiciones de salud precarias (1).

La Defensoría del Pueblo en un análisis sobre la situación carcelaria en nuestro país afirma sobre el hacinamiento: "Trae como consecuencia graves problemas de salud, de violencia, de indisciplina, de carencia en la prestación de servicios (trabajo, educación, asistencia social, deportes, educación, visita conyugal, servicios médicos, etc.), con una clara violación de la integridad física y mental de los reclusos, de su autoestima y de la dignidad humana. Igualmente, el hacinamiento, cuando sobrepasa el nivel crítico, se convierte en una forma de pena cruel, inhumana y degradante. Para la comisión es claro que en los penales que presentan condiciones de hacinamiento crítico, la calidad de vida de los reclusos sufre serios deterioros, al punto que no se pueden considerar sitios seguros ni para los internos, ni para el personal que trabaja con ellos" (2).

La presente investigación se llevó a cabo en el Centro Carcelario y Penitenciario de Mocoa, Putumayo durante el ańo 2013. Es un estudio sin precedentes en el departamento del Putumayo, el cual permitió abordar la compleja situación de salud de esta población cautiva, más aún cuando el centro se ubica en un territorio donde la confrontación armada es una constante, asî como el desplazamiento forzado, los cultivos ilícitos, el escaso desarrollo económico, entre otras problemáticas, que otorgan 
al departamento una connotación diferente con respecto al resto del país. El objetivo de este estudio fue describir la situación de salud de los reclusos en el Centro Penitenciario y Carcelario del Municipio de Mocoa, Putumayo.

\section{MÉTODOS}

Diseńo: Estudio observacional descriptivo trasversal.

Población y muestra: El universo o población estuvo constituido por 642 reclusos del centro penitenciario y/o carcelario del municipio de Mocoa-Putumayo, de los cuales 583 reclusos registran como sexo masculino y 59 reclusos de sexo femenino. Para esta investigación la muestra se calculó con el programa EPI INFO versión 3.5.3; con nivel de confianza del $95 \%$, una frecuencia esperada del $20 \%$ (Enfermedad dentro del penal) y un error estimado del 5\%. El tamańo de la muestra fue de 103 internos de sexo masculino; para la población de sexo femenino se seleccionaron 33 reclusas que aceptaron voluntariamente responder la encuesta. El criterio de selección de la muestra se llevó a cabo por medio de muestreo aleatorio simple.

Métodos para obtener la información: La técnica que se utilizó para la recolección de los datos fue a través de la observación directa, una encuesta estructurada a la población reclusa y la revisión documental de todos los registros individuales de prestación de servicios como fuente de datos secundaria, durante el periodo de enero a diciembre de 2013. Para la recolección de la información se utilizó una guía que evaluó las condiciones sanitarias y ambientales; se aplicó una encuesta auto diligenciada por los reclusos; un formulario con variables de la revisión de los registros de archivos de la prestación del servicio en salud a los reclusos y la guía observacional que, mediante visita de inspección, permitió información sobre las instalaciones físicas, sanitarias, residuos sólidos y líquidos y vigilancia epidemiológica.

Análisis estadístico: Descriptivo, mediante la utilización de variables cualitativas o categóricas que se expresan como frecuencias absolutas y relativas. Para la organización, sistematización y análisis de la información del cuestionario autodiligenciado se agruparon numéricamente los datos en un formato creado en el programa EPI INFO 7.1.3.3, y se realizaron tablas para hacer los respectivos análisis sobre las causas de morbilidad y sus factores asociados de acuerdo a la clasificación internacional CIE 10. En el desarrollo de la investigación se tuvieron en cuenta los parámetros establecidos en la Declaración de Helsinki, las Normas de Buenas Prácticas Clínicas, las Pautas Éticas Internacionales para la Experimentación Biomédica en Seres Humanos y la Resolución No 008430 de 1993.

\section{RESULTADOS}

El enfoque va dirigido a las características sociodemográficas, percepción de salud y enfermedad de los internos, morbilidad, características sanitarias y ambientales, y eventos de interés en salud pública.

\section{Características sociodemográficas}

La muestra encuestada se concentra en el rango de edad de los 20 a 49 ańos. En mayor proporción en el grupo etario entre 19 y 29 ańos de edad (40.4\%) y entre 40 a 49 ańos con un $26.5 \%$. La edad promedio fue de 36 ańos y el $75.7 \%$ de los encuestados correspondían a sexo masculino. En cuanto a grupos étnicos existentes el $30.4 \%$ de los encuestados manifestaron ser de población indígena. El 26.5\% tiene el nivel de escolaridad de secundaria completa. Un $25.7 \%$ registró sobrepeso y $5.1 \%$ obesidad.

\section{Percepción de salud y enfermedad de los internos}

En cuanto el estado de salud de los internos al ingresar al penal, el 77.9\% ( $n=106)$ de los encuestados manifestó que enfermaron luego de su ingreso a la cárcel. En relación a la oportunidad en la prestación de servicios médicos básicos y especializados se determinó que hay una mayor disponibilidad de atención odontológica inmediata, comparado con la atención médica; el 32.1\% de los encuestados manifestó que la asignación de cita tomó un mes y para el 9.4\% nunca les fue asignada (Tabla 1).

Como parte de la encuesta, se evalúo el conocimiento adecuado sobre las infecciones de transmisión sexual (ITS); el 90.4\% afirmó conocer que era una ITS; sin embargo, al presentar diversas opciones de conceptos, $25.7 \%$ respondieron de manera errónea y $19.8 \%$ no respondieron.

Al evaluar el consumo de sustancias psicoactivas se encontró que $35.3 \%$ de los encuestados consumían sustancias psicoactivas, donde $54.2 \%$ manifestó que ya tenían un hábito de consumo desde antes de ingresar al penal, con un tiempo de consumo entre 1 y 4 ańos en el $27.1 \%$ de los encuestados (Tabla 2). 
Los internos de este penal conviven en situación de hacinamiento; el número de internos por celda 0 alojamiento excede los límites permisibles. La revisión registros de prestación de servicios para el ańo 2013 reveló que las principales causas de morbilidad son de tipo infeccioso, infecciones en vías urinarias, dermatitis, bronquitis, conjuntivitis y amebiasis entre las primeras 10 causas. Patologías de tipo crónico como la hipertensión corresponden al $1.1 \%$ de las causas de consulta en la población interna (Tabla 3).

\section{Descripción sanitaria y ambiental}

Los 642 internos (as) se encuentran distribuidos en 8 patios. La capacidad interna real de la cárcel corresponde a 360 internos para el ańo 2013, existiendo una sobreocupación del $84 \%$. La cárcel de Mocoa consta de 5 patios para hombres y mujeres con un rancho o cocina, el área de sanidad, biblioteca, la parte administrativa y una cafetería. Los pisos no son impermeables y carecen de sistemas apropiados para el drenaje de aguas, no se cuenta con seńalización y demarcación de áreas internas, la ventilación e iluminación son inadecuadas en consultorios o área de sanidad y deficientes en las celdas. El calor es excesivo.

\section{Eventos de interés en salud pública}

El sistema de vigilancia en el establecimiento penitenciario y carcelario de Mocoa no se ha implementado, por lo tanto, no se notifican los eventos presentados en ańos anteriores, simplemente se tiene un registro de las enfermedades generales de la población carcelaria.
Tabla 1. Distribución porcentual según tiempo en la prestación del servicio médico y odontológico en los internos (as) de la cárcel de Mocoa-Putumayo, ańo 2013.

\begin{tabular}{lcccc}
\hline $\begin{array}{c}\text { Tiempo en la prestación } \\
\text { del servicio médico }\end{array}$ & $\begin{array}{c}\text { Total de } \\
\text { pacientes } \\
\text { atendidos }\end{array}$ & $\%$ & $\begin{array}{c}\text { Servicio } \\
\text { Odontológico }\end{array}$ & $\%$ \\
\hline Inmediata & 3 & $2.8 \%$ & 16 & $15.1 \%$ \\
Al otro día & 15 & $14.1 \%$ & 11 & $10.5 \%$ \\
A los dos días & 15 & $14.1 \%$ & 11 & $10.5 \%$ \\
A la semana & 22 & $20.7 \%$ & 20 & $19.2 \%$ \\
Al mes & 34 & $32.1 \%$ & 16 & $15.3 \%$ \\
No se ha solicitado & 3 & $2.8 \%$ & 16 & $15.3 \%$ \\
Nunca & 10 & $9.4 \%$ & 12 & $11.5 \%$ \\
Otros & 4 & $3.7 \%$ & 2 & $1.9 \%$ \\
\hline Total & 106 & $100 \%$ & 104 & $100 \%$ \\
\hline
\end{tabular}

Tabla 2. Distribución porcentual según consumo de sustancias psicoactivas en los internos (as) de la cárcel de Mocoa-Putumayo, ańo 2013.

\begin{tabular}{|c|c|c|}
\hline Inicio del consumo de psicoactivas & No. & $\%$ \\
\hline En la cárcel & 14 & $29.1 \%$ \\
\hline Antes de entrar a la cárcel & 26 & $54.1 \%$ \\
\hline No responde & 8 & $16.6 \%$ \\
\hline Total & 48 & $100 \%$ \\
\hline Tipo de sustancia & No. & $\%$ \\
\hline Cigarrillos & 35 & $39.7 \%$ \\
\hline Marihuana & 25 & $28.4 \%$ \\
\hline Alcohol & 15 & $17.1 \%$ \\
\hline Derivados de coca (Cocaína, perica, crack, éxtasis) & 12 & $13.6 \%$ \\
\hline Total & 88 & $100 \%$ \\
\hline Tiempo de consumo & No. & $\%$ \\
\hline 1 a 4 ańos & 13 & $27.1 \%$ \\
\hline 5 a 10 ańos & 10 & $20.1 \%$ \\
\hline Más de 10 ańos & 14 & $29.1 \%$ \\
\hline Menos 1 ańo & 2 & $4.1 \%$ \\
\hline No responde & 9 & $18.7 \%$ \\
\hline Total & 48 & $100 \%$ \\
\hline
\end{tabular}


Tabla 3. Morbilidad general según veinte primeras causas en internos (as) de la Cárcel de Mocoa-Putumayo, 2013.

\begin{tabular}{lcc}
\hline \multicolumn{1}{c}{ Descripción } & No. & $\%$ \\
\hline $\begin{array}{l}\text { Infección de Vías Urinarias, } \\
\text { sitio no especificado }\end{array}$ & 276 & $12.6 \%$ \\
Dermatitis Infecciosa & 150 & $6.9 \%$ \\
Lumbago no especificado & 148 & $6.8 \%$ \\
Gastritis, no especificada & 127 & $5.8 \%$ \\
Bronquitis aguda, & 118 & $5.4 \%$ \\
no especificada & & \\
Conjuntivitis aguda, & 95 & $4.3 \%$ \\
no especificada & & $3.9 \%$ \\
Dolor en articulación & 85 & $2.1 \%$ \\
Cefalea & 47 & $2.1 \%$ \\
Mialgia & 46 & $1.8 \%$ \\
Amebiasis, no especificada & 40 & $1.8 \%$ \\
$\begin{array}{l}\text { Otros dolores abdominales } \\
\text { y los no especificados }\end{array}$ & 40 & $1.6 \%$ \\
Traumatismo, no especificado & 35 & $1.3 \%$ \\
Trastornos de la acomodación & 29 & $1.1 \%$ \\
Hipertensión esencial & $21 \%$ \\
(primaria) & 25 & $03.3 \%$ \\
Infección intestinal bacteriana, \\
no especificada \\
Rinitis vasomotora
\end{tabular}

\section{DISCUSIÓN}

El Departamento del Putumayo, como otros departamentos de la Orinoquia y Amazonía colombianas, se ha caracterizado por las malas condiciones de vida, el bajo nivel educativo, la deficiente infraestructura en salud y desarrollo económico limitado, caracterizado por una fuerte economía informal e ilegal derivada del auge de la coca sumado a la situación de violencia por el conflicto armado interno.

Según el perfil elaborado por el INPEC (Instituto Nacional Penitenciario y Carcelario) en el ańo 2011, de la totalidad de internos condenados en los 139 establecimientos de reclusión a su cargo, 25\% estaban entre los 17 y 27 ańos de edad (3). En concordancia con los resultados de este estudio, la mayoría de los internos tenía un rango de edad entre los 19 y 29 ańos. Lo anterior puede indicar que la juventud es el grupo etario con alta vulnerabilidad para estar involucrados en actos delictivos y en situaciones de violencia.

Los indígenas representaron el $30.4 \%$ de la muestra de la población carcelaria encuestada, constituyéndose en un grupo relevante. Sin embargo, el presente estudio no encontró que esta población fuera objeto de un tratamiento "especial" en razón a su pertenencia étnica.

El centro penitenciario de Mocoa cuenta con 5 patios donde se alojan más de 600 personas, lo cual corresponde a una sobrepoblación muy alta (84\%). Al igual que en otros penales, la cárcel de Mocoa alberga a prisioneros en hacinamiento. Sin embargo, esta proporción es inferior al compararla con otros centros penitenciarios. Para el 2003, según informe de la Defensoría del Pueblo sobre la situación de salud de las cárceles, los penales presentaban un hacinamiento global del $29.3 \%$ (4).

La escolaridad de la población carcelaria se caracteriza por un bajo nivel, inferior al de otras poblaciones reclusas. En el estudio de Mejía et al (5), el 51.2\% había cursado secundaria y $6 \%$ tenían estudios universitarios. A nivel del Departamento del Putumayo la escolaridad global es baja comparada con otros departamentos.

La evaluación de los registros individuales de prestación de servicios (RIPS) de las consultas del 2013, junto con los resultados obtenidos en las encuestas, ayudó a determinar que el comportamiento de morbilidad difiere de los reportes que se realizan en otros penales alrededor del mundo. La revisión de los perfiles de salud de población reclusa por Dumont et al (6) refiere que, aunque el encarcelamiento pueda proporcionar una influencia protectora de la salud y se proporcione refugio y comida a una población generalmente pobre, el efecto protector de la encarcelación sería ilusorio. Condiciones adversas reconocidas como el hacinamiento y las deficiencias en la prestación del servicio conlleva que los internos desarrollen problemas de salud graves. Beckwith et 
al (7) considera que las enfermedades infecciosas se adquieren "antes de", en lugar que "durante" el encarcelamiento. Un dato importante que arrojó la encuesta fue el estado de salud de los internos al ingresar al penal. Un 77.9\% manifestaron que enfermaron luego de ingresar a la cárcel.

El estudio de Mejía et al (5) realiza una descripción de los mecanismos y barreras de acceso a los servicios de salud. Al evaluar el tiempo de espera para acceder a consulta médica, $48,1 \%$ espera 8 días; el 23,4\% entre 1 y 5 días. En la presente investigación, $77.9 \%$ de los encuestados reportaron que eran sanos antes de ingresar al penal y que al ingresar enfermaron, Adicionalmente reportaron una limitada disponibilidad de consulta médica (oportunidad en la prestación). Este resultado puede ser susceptible de sesgos de información y selección y debe ser analizado en consonancia.

Respecto a las infecciones de transmisión sexual, se evalúo inicialmente el conocimiento que tenían los encuestados sobre el tema, donde la mayoría manifestaron saber al respecto, pero al presentar diversos conceptos de ITS, 25\% respondieron de manera errónea. Esto es consecuente otros resultados como el estudio de Galindo et al (1) donde se reportan preconceptos erróneos sobre la forma de transmisión de las ETS. Los casos de ITS estuvieron entre las últimas causas de morbilidad entre la población interna del centro penitenciario de Mocoa.

Se abordó también la situación de consumo de sustancias psicoactivas en el Penal donde el presente estudio reveló un comportamiento similar al obtenido por el Observatorio Argentino de Drogas (8). Un 34\% de los reclusos manifestó haber consumido algún tipo de droga y la marihuana se constituyó en la principal sustancia de acceso y consumo entre los presos. Aunque no se abordó directamente en este estudio, quienes manifestaron consumir sustancias psicoactivas dentro del penal son vulnerables a riesgos en su salud física. El análisis de los Registros Individuales de Prestación de Servicios de Salud no encontró eventos de salud mental, sin embargo, pueden ser subregistrados.

El hacinamiento y las bajas condiciones de vida son reconocidos como entornos de alto riesgo para la transmisión del Virus de Inmunodeficiencia Humana (VIH) (9). Estudios alrededor del mundo reportan comportamientos de riesgo en las cárceles con la consecuente transmisión de este virus. En la revisión de las causas de morbilidad de este penal no se registraron casos de infección por VIH. Nuevamente, puede tratarse de subregistro diagnóstico.
Las enfermedades crónicas no transmisibles se constituyen en un problema de salud pública en el mundo entero siendo la población cautiva susceptible a esta clase de eventos secundarios al sedentarismo e inadecuada alimentación. Nuestra encuesta evaluó la presencia de eventos como sobrepeso/obesidad, hipertensión arterial y diabetes. Una revisión sistemática determinó que los prisioneros de sexo masculino tienen menor riesgo de presentar obesidad (10). Este estudio no mostro diferencias en género y las frecuencias de sobrepeso y obesidad fueron inferiores a las reportadas por Villegas et al (11) (31\% en sobrepeso y $8 \%$ en obesidad).

A nivel general, son muy escasos los reportes sobre los eventos de interés en salud pública configurados por el Ministerio de Protección Social dentro del sistema de vigilancia de este centro penitenciario. La población del presente estudio en situación de hacinamiento, con limitado acceso a servicios básicos de salud, en condiciones de insalubridad, con desconocimiento de aspectos básicos de promoción de la salud, debería ser objeto de reportes de eventos de toda clase. Sin embargo, la evidencia muestra lo contrario. Es claro que el sistema de vigilancia en este centro penitenciario presenta un rezago importante; que quizá se deba a que los proceso de salud no sean direccionados directamente por el INPEC, dado que la EPS Caprecom es la responsable de la atención de los internos y por tanto del reporte al sistema de vigilancia, lo cual puede de alguna forma obstaculizar el flujo oportuno de la información y en la misma medida, repercutir en la aplicación de acciones oportunas en caso de brotes o eventos de gravedad.

En los resultados obtenidos en la evaluación de las características sanitarias y ambientales, es importante resaltar que al igual que en los informes internacionales sobre Derechos Humanos, las condiciones de hacinamiento de los internos también se presentan en este centro penitenciario. En el análisis de Sarkin (12) se reporta como la sobrepoblación en sus penales no ha sido abordada de manera integral; el "amontonamiento" se constituye en un foco de violencia, enfermedad, muerte y humillación, fenómeno que crece día tras día. En este mismo estudio, se menciona como la pobreza en el continente africano se constituye en un factor que precipita no solo el aumento de delitos, sino que se refleja en las condiciones de vida en las que viven los presos. El Putumayo es un departamento caracterizado por las condiciones de pobreza, con un índice de necesidades básicas insatisfechas superior al 90\%, una pobre escolaridad, entre otros factores precipitantes que se ven reflejados en la vida dentro del centro penitenciario. 


\section{REFERENCIAS}

1. Galindo J. Vulnerabilidad en salud de los presos del Penal de Villahermosa, Cali; Colombia [tesis pregrado; digital]. [Cali]: Universidad ICESI; 2012 febr. 48 - 49 p. Disponible en: https://repository.icesi.edu.co/biblioteca_digital/ bitstream/10906/65522/5/vulnerabilidad_salud_presos. pdf (accessed 10 diciembre 2015).

2. Defensoría del Pueblo. Análisis sobre el actual hacinamiento carcelario y penitenciario en Colombia. Bogotá D.C: Defensoría del Pueblo; 2003.

3. Instituto Nacional Penitenciario y Carcelario INPEC. Caracterización y perfilación criminológica y penitenciaria de la población condenada y privada de la libertad en los establecimientos de reclusión del INPEC y propuesta para el direccionamiento del tratamiento penitenciario en Colombia. Bogotá D.C: Instituto Nacional Penitenciario y Carcelario INPEC; 2011.

4. Defensoría del Pueblo. situación del servicio de salud en las cárceles de Colombia. Bogotá D.C: Defensoría del Pueblo; 2003.

5. Mejía-Ortega L, Hernández-Pacheco J, Nieto-López E. Condiciones de accesibilidad a los servicios de salud de las internas e hijos convivientes en el centro de reclusión para mujeres El Buen Pastor de Medellín 2009. Revista Gerencia y Política de Salud; 2011; 10(20): 121-37.

6. Dumont DM, Brockmann B, Dickman S, Alexander N, Rich JD. Public Health and the Epidemic of Incarceration. Annual Review of Public Health. 2012; 33 (1):325-39.

7. Beckwith CG, Zaller ND, Fu JJ, Montague BT, Rich JD. Opportunities to diagnose, treat, and prevent HIV in the criminal justice system. J Acquir Immune Defic Syndr. 2010; 55 (1): S49-55. Doi: 10.1097/QAI.0b013e3181f9c0f7.

8. Observatorio Argentino de Drogas. Estudio Nacional sobre consumo de sustancias Psicoactivas y su relación con la comisión de delitos en población privada de la libertad. Argentina: Observatorio Argentino de Drogas; 2009.

9. Jürgens R, Nowak M, Day M. HIV and incarceration: prisons and detention. J Int AIDS Soc. 2011; 14:26. Doi: 10.1186/1758-2652-14-26.

10. Herbert K, Plugge E, Foster C, Doll H. Prevalence of risk factors for non-communicable diseases in prison populations worldwide: a systematic review. Lancet. 2012; 379(9830):1975-82. Doi: 10.1016/S0140-6736(12)60319-5.

11. Ochoa-Orozco SA, Moreno-Gutiérrez PA, Luis EcheverriCatańo LF, Orozco-Escobar A, Mondragón-Cardona AE, Villegas-Rojas S. Riesgo cardiovascular y de diabetes en población carcelaria de Pereira, Colombia, 2010. Rev. Med. Risaral. 2012; 19 (2): 129-33.
12. Sarkin J. Las cárceles en África: una evaluación desde la perspectiva de derechos humanos. Sur.Rev. int. direitos human. 2008. 5 (9): 22-51. Doi: 10.1590/S180664452008000200003 